\title{
Semen Quality and Fertility of Men Employed in a South African Lead Acid Battery Plant
}

\author{
Thomas G. Robins, MD, MPH, ${ }^{1}$ M.S. Bornman, MBChB, MD, DSC, ${ }^{2}$ Rodney I. Ehrlich, BBusSC, MBChB, \\ DOH, FFCH (SA), ${ }^{3}$ Anthony C. Cantrell, PhD, ${ }^{4,5}$ Elma Pienaar, NDipClinTech, ${ }^{2}$ \\ J awaherlal Vallabh, HDipMedTech, ${ }^{4}$ and Shirley Miller, BA, $\mathrm{DOH}^{6}$
}

\begin{abstract}
Previous studies of the associations of measures of occupational lead exposure with measures of semen quality and infertility among male workers have produced conflicting results. The current study was undertaken to examine these associations among a population of workers with a broad range of measures of current and historical lead exposure. Ninety-seven lead-exposed workers from a South African lead acid battery facility provided semen samples that were analyzed for sperm density, sperm count, sperm motility, sperm morphology, and presence of antisperm antibodies. Questionnaire data were collected for reported histories of sub- or infertility. Current blood leads ranged from 28 to $93 \mu \mathrm{g} / \mathrm{dl}$. Semen lead ranged from 1 to $87 \mu \mathrm{g} / \mathrm{dl}$. Reasonably consistent and significant associations were found between an increased percentage of sperm with abnormal morphology and higher measures of current blood lead, cumulative blood lead, and duration of exposure. An increased percent of immotile sperm was associated only with zinc protoporphyrin (ZPP) among the lead exposure measures. There were no associations of sperm density or sperm count with any of the lead exposure measures. A weak association of increased percent of sperm with antisperm antibodies with increased semen lead was present. There were no consistent associations of measures of lead exposure with measures of fertility or procreativity. This study, while supporting the association of lead exposure with increased risk of abnormal sperm morphology seen in some previous studies, does not lend support to previously reported associations of sperm density or count or infertility with measures of lead exposure. However, the relatively high range of current blood leads, high prevalence of abnormalities in semen quality, and the lack of a control population, suggest that these negative findings should be interpreted with caution. Am. J. Ind. Med. 32:369-376, 1997. ๑1997 Wiley-Liss, Inc.
\end{abstract}

KEY WORDS: reproductive health; semen; spermatogenesis; sperm; infertility; lead; battery workers

${ }^{1}$ Department of Environmental and Industrial Health, University of Michigan School of Public Health, Ann Arbor, Michigan

${ }^{2}$ Department of Urology, University of PretoriaPretoria, South Africa

${ }^{3}$ Department of Community Health, University of Cape Town, Cape Town, South Africa

${ }^{4}$ National Centre for Occupational Health, J ohannesburg, South Africa

${ }^{5}$ Department of Community Health, University of Witwatersrand, Witwatersrand, South Africa

${ }^{6}$ Chemical Workers Industrial Union, J ohannesburg, South Africa

Contract grant sponsor: Medical Research Council of South Africa; Contract grant sponsor: De Beers Chairman's Educational Trust; Contract grant sponsor: Medical Faculty of the University of Cape Town; Contract grant sponsor: University of Michigan Office of the Vice President for Research; Contract grant sponsor: United States Public Health Service.

*Correspondence to: Dr. Thomas G. Robins, University of Michigan, School of Public Health, Ann Arbor, MI 48109-2029; E-mail: trobins@umich.edu

Accepted for publication 5 March 1997

\section{INTRODUCTION}

Only a limited number of studies have addressed the reproductive health of men occupationally exposed to lead [Alexander et al., 1996; Assennato et al., 1986; Coste et al., 1991; Cullen et al., 1984; Gennart et al., 1992; Jiang et al., 1992; Lancranjan et al., 1975; Lerda, 1992; Wildt et al., 1983]. The findings of these studies are not entirely consistent with respect to the effect of lead on measures of semen, quality including sperm density, sperm count, motility, and morphology and on measures of fertility. Moreover, the ranges of blood leads for which positive studies have reported results have varied. Animal studies have reported paternally transmitted effects of lead on fertility and im- 
paired spermatogenesis at exposure levels comparable to higher human occupational levels [Thomas and Brogan, 1983].

The current study, which was part of larger study of health effects of lead exposure, was undertaken to examine the association between measures of lead exposure and measures of semen quality and fertility among a population of South African lead acid battery workers. Because historical exposure to lead in this industry had been substantial and because of the presence of a number of temporary workers with shorter term exposures, it was expected that a broad distributions of current blood lead and cumulative blood lead would be present in the population enabling a particularly fruitful examination of lead reproductive effects.

\section{METHODS}

A cross-sectional study was conducted in a workforce of approximately 400 men in a lead acid battery plant in the city of East London on the east coast of South Africa. The work force is predominantly African; most employees have grown up in rural districts of the Eastern Cape Province. All permanent production workers were invited to participate. Temporary workers (on short contracts) over 37 years of age were also invited, to add a group of older short-service workers to the study group. The batteries are assembled using a conventional process [Burgess, 1995]. Exposures were to both inorganic lead and lead oxide fume and dust.

\section{Questionnaire}

A questionnaire was administered by a trained interviewer in the language of the subject. Questions inquired about demographic details and reproductive history (number of children fathered before and since commencement of lead exposure, periods of infertility, sexual functioning), smoking, and alcohol intake.

\section{Exposure Measurement}

A detailed occupational history was taken of jobs in this plant and elsewhere, including questions about exposure to heavy metals both at and outside of work. Service periods were checked against company records, and discrepancies were remedied by re-contacting the company and employee if necessary. Blood lead levels from routine testing were available for some long service workers from other plants from 1974, but for most of the workforce only from 1983. The frequency of measurement had increased in recent years and particularly since 1991, when lead regulations were introduced in South Africa.

For this study, heparinized whole blood was collected in lead-free Vacutainer ${ }^{\circledR}$ tubes in the facility's medical department. Blood lead was measured by graphite furnace atomic absorption spectroscopy by a laboratory participating in the
United Kingdom National External Quality Assessment Scheme. Zinc protoporphyrin (ZPP) was measured in the same specimen on Aviv Hematofluorimeter and expressed in micrograms per gram hemoglobin ( $\mu \mathrm{g} / \mathrm{g} \mathrm{Hb})$.

A cumulative exposure index in years $\times$ blood lead $(\mu \mathrm{g} / \mathrm{dl})$ was constructed by summing the annual average blood lead over all years of exposure. For the years before routine blood lead testing, the average of the first two available measurements was attributed to each of these preceding years.

\section{Semen Analyses}

Semen samples were collected by masturbation after a requested period of 3 days of abstinence from sexual activity. After liquefaction, complete semen analyses were performed according to the WHO [1992] methods and standards, including assessment of sperm density, total sperm count (million sperm per ejaculate, ejaculate volume $\times$ sperm density), differential sperm motility scoring, supravital staining (for percentage live sperm), measurement of sperm $\mathrm{pH}$, seminal volume and viscosity, and the presence of round cells and agglutinates. Semen was also screened for the presence of antibodies directed at the sperm membrane; the presence of these antibodies is considered specific for immunological infertility. In the presence of coating antibodies, motile sperm will have latex particles adhering to them. The diagnosis of immunological infertility is suspected when $10-39 \%$ of the motile spermatozoa are covered by particles and if $40 \%$ or more of the spermatozoa are coated, immunological infertility is highly probable (Direct SperMar IgG Test ${ }^{\circledR}$, FeriPro, N.V. St Martens-Latem, Belgium).

Smears were made and later stained with Papanicolaou stain before evaluation by a single technologist trained to use the Tygerberg strict criteria for sperm morphology evaluation [Kruger, 1986]. Semen swabs were taken from 92 subjects for Chlamydia enzyme immune assay (EIA) (IDEIA III, Dako Diagnostics, UK) to detect $C$. trachomatis. Dacron swabs of aluminum shafts with prescored plastic handles provided with the kit were dipped in semen specimens and then immersed in $1 \mathrm{ml}$ EIA transport medium and, once in the laboratory, vortexed before and after boiling for $15 \mathrm{~min}$ to release the antigen from swabs. The test was carried out on $200 \mu \mathrm{l}$ of transport medium according to the manufacturer's instruction (Dako Diagnostics, UK). In five subjects, the seminal volume was low and swabs could not be taken.

Semen was transferred to 2.0-ml Eppendorf cryotubes (Eppendorf ${ }^{\circledR}$, Cat. No. 0030 120.94) for semen lead determination and stored at $-20^{\circ} \mathrm{C}$ until the lead determinations were done at the National Centre for Occupational Health, Johannesburg, using graphite furnace atomic absorption spectroscopy (GFAA) on a Perkin-Elmer 5000.

Frozen semen specimens were thawed at room temperature. Aliquots $(0.1 \mathrm{ml})$ were taken, added to $0.9 \mathrm{ml} 0.1 \%$ 
Triton X100 solution, using an automatic Hamilton dilutor, and mixed thoroughly before analysis in duplicate. The concentration of lead in the semen specimens was calculated from a standard curve obtained by adding aliquots of a standard commercial solution of lead to semen from a nonexposed donor, in order to eliminate matrix effects.

\section{Data Analysis}

The study participants were categorized by level of the various exposure measures. For most measures, four categories were chosen that divided the participants roughly by quartile of exposure. Arithmetic means and standard deviations were calculated for each of the exposure concentration groups for various measures of semen quality. In addition, the prevalence of below-normal values for semen quality variables were determined based on the World Health Organization (WHO) standard values for evaluation of infertility [WHO, 1992]. Mantel-Cochran linear tests for trend were conducted to examine these bivariate associations. In addition, a least-squares regression model was fitted to each semen quality variable to analyze linear trends with exposure measures. Covariates evaluated in these models included age, alcohol consumption, smoking, and sexual abstinence before sample collection. Logistic models that considered the probability of semen parameters as below WHO criteria also were examined using the same covariates.

\section{RESULTS}

A total of 382 employees took part in the main study representing a response rate of over $95 \%$ of those invited. Among the 382 participants, the average current blood lead was $53 \mu \mathrm{g} / \mathrm{dl}$, with the lowest being 23 and the highest 110 . Thirty-eight percent of the workers had current blood leads between the U.S. standard (for a single sample) of $60 \mu \mathrm{g} / \mathrm{dl}$ and the South African standard of $80 \mu \mathrm{g} / \mathrm{dl}$. Twelve workers (3.1\%) had blood lead levels above $80 \mu \mathrm{g} / \mathrm{dl}$.

Of the 382 participants, almost 200 volunteered to participate in the reproductive substudy. Owing to later drop out and logistical difficulties, a total of 151 men eventually attempted to provide a semen sample, of whom 97 were successful. Characteristics of those who provided usable semen samples as compared to all other participants are shown in Table I. The semen donors were significantly younger than the other study participants but did not differ significantly (at $\alpha=0.05$ level) with respect to height, weight, mean years at the facility, cumulative blood lead, current blood lead, zinc protoporphyrin, smoking, alcohol use, reported problems with erectile function, or reported history of infertility. When the 97 semen donors were compared to the 54 men unable to produce a sample, the only differences reaching statistical significance were that the donors were more likely to be current smokers $(59 \%$ vs
TABLE I. Characteristics of Semen Donors and Other Participants in Study of South African Lead Acid Battery Workers: 1994

\begin{tabular}{lcc} 
& $\begin{array}{c}\text { Semen } \\
\text { donors }\end{array}$ & $\begin{array}{c}\text { Other study } \\
\text { participants }\end{array}$ \\
\hline Number & 97 & 285 \\
Mean age (s.d.) & $38.3(7.9)$ & $42.3(8.2)^{*}$ \\
Mean height, cm (s.d.) & $169.1(7.2)$ & $169.0(6.0)$ \\
Mean weight, kg (s.d.) & $75.5(14.8)$ & $75.5(13.9)$ \\
Mean years at facility, years (s.d.) & $11.2(5.7)$ & $11.8(7.3)$ \\
Mean cumulative blood lead, & & \\
$\quad$ years $\times \mu$ g/dl (s.d.) & $709.8(449.7)$ & $716.4(492.2)$ \\
Mean current blood lead, $\mu$ g/dl (s.d.) & $53.8(11.2)$ & $53.5(13.3)$ \\
Mean ZPP $\mu$ g/g Hgb (s.d.) & $13.3(7.9)$ & $12.7(9.8)$ \\
Current smokers (\%) & 58.8 & 50.1 \\
Current drinkers (\%) & 74.2 & 64.9 \\
Erection problem (\%) & 33.0 & 26.3 \\
Organic erection problem (\%) & 17.5 & 13.7 \\
History of infertilityc & & \\
$\quad$ Only since employment at facility (\%) & 18.8 & 12.3 \\
Prior to employment at facility (\%) & 3.1 & 9.1 \\
$\quad$ None & 78.1 & 78.6 \\
\hline
\end{tabular}

$* \mathrm{P}<0.01$, t test.

${ }^{a}$ Does your wife or partner have trouble exciting you enough for you to get or keep an erection?

${ }^{b}$ Erection problem plus no to Have you woken from sleep during the night or in the morning with a full erection any time in the past month?

'Did your wife or steady partner ever try to get pregnant for one full year or longer without success?

$39 \%$ ) and less likely to report infertility prior to employment at the facility ( $3 \%$ vs $13 \%$ ). In comparison to the 231 men who did not participate in the reproductive component of the study, the only significant differences were that the semen donors were younger (mean age of 38 vs 43 years) and more likely to report a history of infertility only since employment at the facility (19\% vs $9 \%)$.

The distribution of measured semen parameters among the 97 semen donors is shown in Table II. Both mean sperm density and motility were well above the respective values for normality (20 million/ml and 50\%). For each of three of the semen quality parameters, sperm density, total sperm count, and motility, approximately $20 \%$ of the participants were below WHO criteria. In contrast $97 \%$ of the participants evidenced less than $15 \%$ of sperm with normal morphology. Twelve percent of the participants had $10 \%$ or greater of sperm with detectable antisperm antibodies. The mean sample volume was $2.3 \mathrm{ml}$. Chlamydia EIA was positive on 4 of 92 samples tested (4.3\%).

Continuous measures of semen quality by measures of lead exposure and fertility history are shown in Table III. Among the 97 semen donors, current blood leads ranged from 28 to $93 \mu \mathrm{g} / \mathrm{dl}$ and cumulative blood lead was within 
TABLE II. Distribution of Semen Parameters Among the 97 Semen Donors in Study of South African Lead Acid Battery Workers: 1994

\begin{tabular}{|c|c|c|c|}
\hline & $\begin{array}{l}\text { Mean } \\
\text { (s.d.) }\end{array}$ & Range & $\begin{array}{c}\% \text { of } \\
\text { subjects }\end{array}$ \\
\hline Sperm density (million/ml) & $72.7(59.9)$ & $0-300$ & \\
\hline$<20$ & & & 20.6 \\
\hline Sperm count (million) & $178.6(193.8)$ & $0-957$ & \\
\hline$<40$ & & & 22.7 \\
\hline Motility (\% motile) & $60.8(17.3)$ & $33-100$ & \\
\hline$<50$ & & & 22.7 \\
\hline Morphology (\% normal) & $4.3(4.3)$ & $0-17$ & \\
\hline$<5$ & & & 71.1 \\
\hline $5-15$ & & & 25.8 \\
\hline$>15$ & & & 3.1 \\
\hline Abstinence (days) & $7.2(14.1)$ & $0.5-90$ & \\
\hline$\leq 1$ day & & & 4.3 \\
\hline 2 days & & & 31.2 \\
\hline$\geq 3$ days & & & 64.5 \\
\hline Semen lead ( $\mu \mathrm{g} / \mathrm{dl})$ & $9.6(10.6)$ & $1.0-87.0$ & \\
\hline \multicolumn{4}{|c|}{ Percent of sperm with antisperm } \\
\hline antibodies $^{\mathrm{a}}$ & $6.9(20.6)$ & $0-100$ & \\
\hline$<10$ & & & 87.6 \\
\hline $10-30$ & & & 4.1 \\
\hline$>30$ & & & 8.2 \\
\hline
\end{tabular}

aSee Methods for description of assay.

the range of $26-2,618 \mu \mathrm{g} / \mathrm{dl} \times$ years. The total duration of exposure ranged from 0.5 to 32 years, and the ZPP was withina range of $1-41 \mu \mathrm{g} / \mathrm{g}$ of hemoglobin. Twenty-one of the participants reported a history of no pregnancy with a wife or steady partner after trying for 1 year or longer. Of these 21,18 developed this problem only after beginning to work at a lead-using facility.

Neither sperm density nor total sperm count was significantly associated with any of the measures of lead exposure. Sperm density and total count were both weakly associated with a reported history of infertility and also, as expected, with abstinence prior to the provision of a sample. Among the measures of lead exposure, sperm motility was significantly associated only with ZPP. Sperm motility was also significantly associated with history of infertility, however in an "unexpected" direction. Sperm morphology was significantly associated with total duration of exposure and somewhat associated with both current and cumulative blood lead.

The percentage of subjects with dichotomized measures of semen quality by measures of exposure and fertility history is presented in Table IV. Neither having a total sperm count of $<40$ million nor a sperm density of $<20$ million per milliliter was associated with any of the measures of lead exposure or with infertility, with the exception of a signifi- cant association between sperm density of $<20$ million per milliliter and semen lead in the "unexpected" direction (i.e., higher semen lead was associated with a smaller percentage of subjects with low density). Motility less than 50\% was not associated with any of the measures of lead exposure and was again associated with infertility in an unexpected direction. Having less than 5\% of sperm with normal morphology was significantly associated with cumulative blood lead and weakly associated with both current blood lead and total duration of exposure. Having greater than or equal to $10 \%$ of sperm evidencing antisperm antibodies was not significantly associated with any of the parameters measured. Reporting an organic erection problem was somewhat associated with total duration of exposure and weakly associated with a history of infertility and with ZPP.

In multivariable regression models that controlled for age, alcohol, smoking, and pretest sexual abstinence, the associations of current blood lead, cumulative blood lead, and total duration of exposure with morphology were generally less striking than in the bivariate analyses shown in Tables III and IV. The only ones of these models for which the $P$-value for the exposure coefficient was $<0.15$ were the linear model of duration of exposure $(P=0.13)$ and the logistic model (outcome was probability of less than $5 \%$ of sperm with normal morphology) of current blood lead $(P=$ $0.06)$.

In a multivariable linear regression model, the association between the ZPP and motility was no longer statistically significant $(P=0.12)$.

A multivariable linear model relating semen lead with percent of sperm evidencing antisperm antibody was highly significant for the exposure coefficient $(P=0.001)$. However, when a single outlier, who had both the highest percentage of antisperm antibody (100\%) and the highest semen lead $(87 \mu \mathrm{g} / \mathrm{dl})$ in the study, was removed from the model, the association disappeared $(P=0.80)$.

The association of reported history of infertility with organic erection problem approached significance in the multivariable logistic model $(P=0.09)$.

A procreativity ratio was calculated for each subject defined as: the average number of children fathered per year between age 18 and 40 after beginning work at the facility divided by the average number of children fathered per year between age 18 and 40 before beginning to work at the facility. In a multivariable linear model, a lower procreativity ratio was strongly associated with a lower sperm count and sperm density ( $P$-values of 0.002 and 0.009 , respectively).

\section{DISCUSSION}

In this study of South African lead acid battery workers with current blood lead ranging from 28 to $93 \mu \mathrm{g} / \mathrm{dl}$ and a mean of 13.3 years of lead exposure, only weak evidence 
TABLE III. Continuous Measures of Semen Quality by Measures of Lead Exposure and Fertility History Among South African Lead Acid Battery Workers: 1994

\begin{tabular}{|c|c|c|c|c|c|c|}
\hline & $\mathbf{N}$ & $\begin{array}{c}\% \geq 3 \\
\text { days } \\
\text { abstinence }\end{array}$ & $\begin{array}{c}\text { Density } \\
\text { (million/ml) }\end{array}$ & $\begin{array}{c}\text { Count } \\
\text { (million) }\end{array}$ & $\begin{array}{c}\text { Motility } \\
\text { (\% motile) }\end{array}$ & $\begin{array}{l}\text { Morphology } \\
\text { (\% normal) }\end{array}$ \\
\hline \multicolumn{7}{|l|}{ Current blood Pb ( $\mu \mathrm{g} / \mathrm{dl})$} \\
\hline $28-39$ & 11 & 72.7 & $65.6(50.7)^{\mathrm{a}}$ & $166.5(156.2)$ & $62.4(13.4)$ & $5.8(3.9)$ \\
\hline $40-59$ & 58 & 53.4 & $70.9(60.5)$ & $162.6(190.5)$ & $60.7(17.2)$ & $4.9(4.7)$ \\
\hline $60-93$ & 28 & 67.9 & $79.1(63.4)$ & $216.6(214.0)$ & $60.4(19.5)$ & $2.6(2.7)$ \\
\hline Test for trend, P-value & & 0.83 & 0.09 & 0.39 & 0.21 & 0.16 \\
\hline \multicolumn{7}{|c|}{ Cum. blood Pb (years $\times \mu \mathrm{g} / \mathrm{dl})$} \\
\hline $26-373$ & 21 & 66.7 & $65.0(52.1)$ & $146.9(165.1)$ & $56.8(16.5)$ & $5.1(4.5)$ \\
\hline $374-539$ & 22 & 63.6 & $74.4(61.5)$ & $208.7(260.9)$ & $63.7(20.7)$ & $4.7(5.3)$ \\
\hline $540-807$ & 23 & 60.9 & $62.1(47.4)$ & $136.0(117.8)$ & $62.2(14.9)$ & $4.0(3.3)$ \\
\hline $808-2,618$ & 31 & 58.1 & $84.5(71.6)$ & $210.3(200.9)$ & $60.4(17.2)$ & $3.9(4.0)$ \\
\hline Test for trend, P-value & & 0.05 & 0.23 & 0.47 & 0.78 & 0.14 \\
\hline \multicolumn{7}{|l|}{ Total dur. exposure (years) } \\
\hline $0.5-6.4$ & 18 & 61.1 & $80.8(58.2)$ & $213.0(224.6)$ & $60.1(15.5)$ & $5.5(5.4)$ \\
\hline $6.5-9.9$ & 35 & 68.6 & $66.0(55.2)$ & $151.3(193.4)$ & $63.5(19.9)$ & $4.6(4.4)$ \\
\hline $10.0-13.9$ & 21 & 71.4 & $79.8(66.4)$ & $214.7(179.8)$ & $57.8(12.9)$ & $4.1(3.9)$ \\
\hline $14-32$ & 23 & 43.5 & $69.9(64.6)$ & $160.4(184.2)$ & $60.0(18.5)$ & $3.4(3.4)$ \\
\hline Test for trend, P-value & & 0.31 & 0.68 & 0.63 & 0.68 & 0.04 \\
\hline \multicolumn{7}{|l|}{$\mathrm{ZPP}(\mu \mathrm{g} / \mathrm{g} \mathrm{Hb})$} \\
\hline $1-6.7$ & 24 & 66.7 & $53.8(45.2)$ & $133.5(110.9)$ & $66.5(16.9)$ & $4.5(4.1)$ \\
\hline $6.8-11.7$ & 23 & 60.9 & $71.0(44.5)$ & $149.5(153.1)$ & $62.0(13.7)$ & $3.6(3.6)$ \\
\hline $11.8-18.1$ & 22 & 59.1 & $99.0(80.8)$ & $268.1(253.1)$ & $59.5(17.3)$ & $5.1(5.0)$ \\
\hline $18.2-41$ & 24 & 60.9 & $74.4(62.1)$ & $182.6(225.8)$ & $56.6(20.0)$ & $3.9(4.4)$ \\
\hline Test for trend, P-value & & 0.39 & 0.56 & 0.60 & 0.04 & 0.82 \\
\hline \multicolumn{7}{|l|}{ Semen lead $(\mu \mathrm{g} / \mathrm{dl})$} \\
\hline$<4$ & 24 & 50 & $52.8(48.5)$ & $128.3(173.7)$ & $59.6(17.0)$ & $5.1(4.9)$ \\
\hline $4-6.9$ & 26 & 81.3 & $71.4(55.6)$ & $187.7(179.9)$ & $59.8(13.1)$ & $4.4(4.0)$ \\
\hline $7-11.4$ & 17 & 70.6 & $88.1(52.9)$ & $250.6(233.2)$ & $65.3(16.5)$ & $3.3(3.3)$ \\
\hline $11.5-87$ & 22 & 77.3 & $90.8(72.7)$ & $186.4(181.1)$ & $56.2(18.1)$ & $5.2(4.7)$ \\
\hline Test for trend, P-value & & 0.47 & 0.20 & 0.71 & 0.51 & 0.76 \\
\hline \multicolumn{7}{|l|}{ History of infertilityb } \\
\hline Yes & 21 & 38.1 & $59.6(35.8)$ & $139.7(105.5)$ & $69.3(14.7)$ & $4.9(4.1)$ \\
\hline No & 75 & 35.2 & $77.3(64.6)$ & $191.9(211.3)$ & $57.9(16.8)$ & $4.3(4.3)$ \\
\hline $\mathrm{t}$ test, $\mathrm{P}$-value & & & 0.11 & 0.12 & 0.006 & 0.57 \\
\hline \multicolumn{7}{|l|}{ Abstinence } \\
\hline$\leq 1$ day & 4 & & $23.3(29.0)$ & $12.5(14.9)$ & $75.5(24.2)$ & $4.8(6.6)$ \\
\hline 2 days & 29 & & $54.9(45.9)$ & $118.8(131.6)$ & $59.6(14.3)$ & $5.3(4.4)$ \\
\hline$\geq 3$ days & 60 & & $87.1(64.1)$ & $227.6(213.3)$ & $60.1(17.4)$ & $4.0(4.1)$ \\
\hline Test for trend, P-value & & & 0.07 & 0.07 & 0.42 & 0.54 \\
\hline
\end{tabular}

aMean (s.d.).

${ }^{b}$ No pregnancy after trying for 1 year or longer.

was found of a direct effect of lead on spermatogenesis. In several bivariate and multivariable analyses, significant to borderline significant associations were found between percent of sperm with abnormal morphology and increased current blood lead, cumulative blood lead, and duration of exposure. The only association of percentage motile sperm with parameters of lead exposure was the relatively weak one with ZPP. No associations of lead exposure parameters with either sperm density or total sperm count were found. 
TABLE IV. Percentage of Subjects with Dichotomized Measures of Semen Quality by Measures of Lead Exposure and Fertility History in Study of South African Lead Acid Battery Workers: 1994

\begin{tabular}{|c|c|c|c|c|c|c|c|}
\hline & $\mathbf{N}$ & $\begin{array}{l}\text { Organic } \\
\text { erection } \\
\text { problem }\end{array}$ & $\begin{array}{c}\text { Normal } \\
\text { morph. } \\
<5 \%\end{array}$ & $\begin{array}{l}\text { Motility } \\
<50 \%\end{array}$ & $\begin{array}{l}\text { Antisperm } \\
\mathrm{Ab} \geq 10 \%\end{array}$ & $\begin{array}{c}\text { Density } \\
<20 \text { million } / \mathrm{ml}\end{array}$ & $\begin{array}{c}\text { Count } \\
<40 \text { million }\end{array}$ \\
\hline \multicolumn{8}{|l|}{ Current blood Pb ( $\mu \mathrm{g} / \mathrm{dl})$} \\
\hline $28-39 \mu \mathrm{g} / \mathrm{dl}$ & 11 & 9.1 & 54.5 & 18.2 & 0.0 & 18.2 & 18.2 \\
\hline $40-59 \mu \mathrm{g} / \mathrm{dl}$ & 58 & 20.7 & 65.5 & 24.1 & 3.4 & 22.4 & 25.9 \\
\hline $60-93 \mu \mathrm{g} / \mathrm{dl}$ & 28 & 14.3 & 85.7 & 21.4 & 3.6 & 17.6 & 17.9 \\
\hline Test for trend, P-value & & 0.69 & 0.12 & 0.62 & 0.29 & 0.94 & 0.99 \\
\hline \multicolumn{8}{|c|}{ Cum. blood Pb (years $\times \mu \mathrm{g} / \mathrm{dl})$} \\
\hline $26-373$ & 21 & 19.0 & 61.9 & 33.3 & 0.0 & 14.3 & 23.8 \\
\hline $374-539$ & 22 & 9.1 & 68.2 & 27.3 & 4.5 & 18.2 & 22.7 \\
\hline $540-807$ & 23 & 26.1 & 69.6 & 13.0 & 0.0 & 26.1 & 26.1 \\
\hline $808-2,618$ & 31 & 16.1 & 80.6 & 19.4 & 6.5 & 22.6 & 19.4 \\
\hline Test for trend, $\mathrm{P}$-value & & 0.99 & 0.01 & 0.40 & 0.27 & 0.39 & 0.31 \\
\hline \multicolumn{8}{|l|}{ Total dur. exposure (years) } \\
\hline $0.5-6.4$ & 19 & 15.8 & 52.6 & 21.1 & 0.0 & 11.1 & 11.1 \\
\hline $6.5-9.9$ & 35 & 14.3 & 65.7 & 25.7 & 2.9 & 22.9 & 28.6 \\
\hline $10.0-13.9$ & 21 & 19.0 & 81.0 & 19.0 & 0.0 & 14.3 & 14.3 \\
\hline $14-32$ & 23 & 21.7 & 82.6 & 21.7 & 8.7 & 30.4 & 30.4 \\
\hline Test for trend, P-value & & 0.08 & 0.12 & 0.77 & 0.18 & 0.24 & 0.42 \\
\hline \multicolumn{8}{|l|}{$\mathrm{ZPP}(\mu \mathrm{g} / \mathrm{g} \mathrm{Hb})$} \\
\hline $1-6.7$ & 24 & 20.8 & 79.2 & 20.8 & 0.0 & 29.2 & 37.5 \\
\hline $6.8-11.7$ & 23 & 21.7 & 82.6 & 21.7 & 4.3 & 17.4 & 26.1 \\
\hline $11.8-18.1$ & 22 & 13.6 & 59.1 & 27.3 & 9.1 & 18.2 & 13.6 \\
\hline $18.2-41$ & 24 & 12.5 & 70.8 & 25.0 & 0.0 & 20.8 & 16.7 \\
\hline Test for trend, P-value & & 0.15 & 0.54 & 0.35 & 0.93 & 0.54 & 0.21 \\
\hline \multicolumn{8}{|l|}{ Semen lead ( $\mu \mathrm{g} / \mathrm{dl})$} \\
\hline$<4$ & 24 & 16.7 & 58.3 & 29.2 & 0.0 & 25.0 & 25.0 \\
\hline $4-6.9$ & 26 & 11.5 & 69.2 & 23.1 & 3.8 & 19.2 & 15.4 \\
\hline $7-11.4$ & 17 & 17.6 & 82.4 & 5.9 & 5.9 & 17.6 & 17.6 \\
\hline $11.5-87$ & 22 & 22.7 & 68.2 & 27.3 & 4.5 & 9.1 & 13.6 \\
\hline Test for trend, P-value & & 0.20 & 0.78 & 0.92 & 0.46 & 0.03 & 0.27 \\
\hline \multicolumn{8}{|l|}{ History of infertilitya } \\
\hline Yes & 21 & 28.6 & 52.4 & 4.8 & 9.5 & 14.3 & 19.0 \\
\hline No & 75 & 14.7 & 65.3 & 28.0 & 13.3 & 21.3 & 22.7 \\
\hline t test, P-value & & 0.14 & 0.28 & 0.03 & 0.64 & 0.47 & 0.72 \\
\hline \multicolumn{8}{|l|}{ Abstinence } \\
\hline$\leq 1$ day & 4 & 75.0 & 50.0 & 25.0 & 0.0 & 50.0 & 100.0 \\
\hline 2 days & 29 & 17.2 & 48.3 & 27.6 & 13.8 & 24.1 & 27.6 \\
\hline$\geq 3$ days & 60 & 13.3 & 70.0 & 20.0 & 11.7 & 15.0 & 13.3 \\
\hline Test for trend, P-value & & 0.37 & 0.31 & 0.48 & 0.50 & 0.25 & 0.31 \\
\hline
\end{tabular}

aNo pregnancy after trying for 1 year or longer.

With respect to measures of fertility or sexual functioning, there was a borderline association of the history of no pregnancy after trying for longer than or equal to 1 year with both lower total sperm count and sperm density. There was a significant (unexpected) positive relationship of this infertility measure with percentage motile sperm. In addition, a measure of the ratio of procreativity after the commencement of lead exposure as compared to prior to lead exposure was significantly associated with lower total sperm count and sperm density. This last finding raises the possibility that changes in these sperm parameters affecting fertility have taken place in subjects in this population over time; how- 
ever, such changes are difficult to associate with lead exposure given the lack of association of density and total count with direct measures of current or cumulative exposure. Finally, the percentage of sperm evidencing presence of anti-sperm antibodies on their surface was positively associated with semen lead in initial analyses. Such a positive association could suggest a mechanism for infertility associated with lead; that is, damage by lead to the blood testis barrier would allow lead to appear in semen and expose spermatogenetic cells to blood increasing the likelihood of the development of antisperm antibodies that have been associated with infertility in non-lead-exposed populations. However, further analysis demonstrated that this association was completely driven by a single high outlier, which may have represented a contaminated semen specimen, casting doubt on the validity of the initial finding.

Because of frequent subjective complaints of decreased sexual functioning among the study population, questions about erectile function were included in the survey. Erectile problems of probable organic origin were somewhat associated with total duration of exposure but with no other measures of lead exposure.

The interpretation of our results with reference to previous research must take into consideration the inherent strengths and weaknesses of this study. As has been true of most studies requiring voluntary donation of semen samples, the successful participation rate was low. Although more than one-half of the study participants volunteered for the reproductive portion of the study, only one quarter of the participants eventually provided usable semen samples. The failure rate of $36 \%$ (97 of 151 would be donors were successful) is close to that reported for men of similar backgrounds by the laboratory performing the analyses. However, the semen donors were representative of the total study population with respect to duration of exposure, measures of blood lead and ZPP, smoking and drinking histories, and reported history of decreased fertility or problems with sexual function. These findings suggest that little selection bias was introduced by the relatively low successful participation rate in the reproductive portion of the study.

Logistical considerations in this cross-sectional study permitted the collection of only one semen sample from each participant. The validity of semen analysis improves when repeated samples are taken, although a single measurement is adequate to characterize the lowest and highest tails of the distributions [Schrader et al., 1988].

Another advantage of this study is the relatively stability of the work force and the availability of historical employment and blood lead monitoring data allowing the calculation of cumulative measures of blood lead and duration of exposure. In addition, the inclusion of a group of temporary workers resulted in relatively broad distributions of current and cumulative measures of blood lead. Nonethe- less, the study is somewhat limited in that, owing to the substantial workplace exposure, the lowest blood lead present among the semen donors was $28 \mu \mathrm{g} / \mathrm{dl}$. In light of this, the unavailability of a truly unexposed comparable population is a significant weakness.

This study provides limited further evidence that some measures of spermatogenesis show a dose-related impairment among workers with relatively high blood leads. An increased percentage of sperm with abnormal morphology at higher exposure levels has been previously reported in several studies [Lancrajan et al., 1975; Lerda, 1992]. Lancrajan et al. found an increase in prevalence of abnormal sperm morphology related to exposure among battery factory workers with current blood lead concentrations from 41 to $75 \mu \mathrm{g} / \mathrm{dl}$. The Lerda study reported that three groups of battery workers with mean blood lead of about 90, 65, and $50 \mu \mathrm{g} / \mathrm{dl}$ showed increased abnormalities in morphology compared to control subjects with mean blood leads of approximately $20 \mu \mathrm{g} / \mathrm{dl}$. In two studies in which the range of blood lead was considerably lower than the current one, no dose relation with sperm morphology was found. Alexander et al. [1996] found no association in a study of 119 workers in a lead smelter in which blood leads ranged from $<15$ $\mu \mathrm{g} / \mathrm{dl}$ to approximately 50 or $60 \mu \mathrm{g} / \mathrm{dl}$. A study by Wildt et al. [1983] comparing two groups with mean blood leads of 45 versus $22 \mu \mathrm{g} / \mathrm{dl}$ also found no effect on morphology.

In contrast to several prior studies, no association of measures of lead exposure with total sperm count or sperm density were found. The previously cited Lancrajan and Alexander studies, as well as a study by Assenato et al. [1987], found such a relationship. The Wildt study, and another study by Jiang et al. [1992], both of which had lower levels of exposure, did not find such an association. The Lerda study also found that the exposed battery workers had decreased density and motility as compared to the controls. However, Lerda found no dose-response among the three groups of lead-exposed battery workers so that his findings actually are consistent with those of the current study which had blood leads in a similar range.

Despite the lack of a dose-response with lead exposures for most semen parameters in this study, the overall prevalence of abnormalities in semen quality was relatively high and comparable to previous studies of lead-exposed workers with blood leads in a similar range. Approximately $20 \%$ of the subjects evidenced sperm density less than 20 million per milliliter, total sperm count less than 40 million and percentage motile sperm less than $50 \%$. For morphology, the abnormalities were substantially higher than had been reported in previous studies with $70 \%$ having less than $5 \%$ sperm with normal morphology and more than $95 \%$ having less than $15 \%$ of sperm with normal morphology. However, in the same laboratory conducting semen analyses for the current study, among (non-lead-exposed) men being evaluated for vasectomy (so-called "proven fertile fathers"), the 
mean percentage of morphologically normal sperm was $4.5 \%$, comparable to the mean of $4.3 \%$ in current study. Nonetheless, the failure to find a dose-response for some of these semen parameters with measures of exposure may not rule out a lead-related effect entirely.

Several previous reports have suggested an association of measures of lead concentrations in blood and/or the semen with sub- or infertility. In a study of 74 battery workers with a mean blood lead of $46.3 \mu \mathrm{g} / \mathrm{dl}$, Gennart et al. [1992] reported a significant decrease in fertility after beginning work with lead, as compared to prior to work with lead. Alexander et al. also reported a significant association of blood lead with decreased fertility. By contrast, Coste et al. [1991] found no association among 229 lead-exposed workers with blood leads ranging from $<40 \mu \mathrm{g} / \mathrm{dl}$ to $>60$ $\mu \mathrm{g} / \mathrm{dl}$.

Saaronen et al. [1987] found semen lead significantly higher in 79 infertile men, as compared to 39 fertile men (means of $3.2 \mu \mathrm{g} / \mathrm{dl}$ and $1.7 \mu, \mathrm{g} / \mathrm{dl}$ respectively). Jockenhovel et al. (1990) reported similar significant findings with mean semen lead concentration in infertile men of $11.3 \mu \mathrm{g} / \mathrm{dl}$ versus 5.6 in fertile men. However, as in the current study, neither of these two studies nor an additional study by Plechaty et al. [1977] found significant associations between measures of sperm count or sperm density and semen lead.

In summary, this study, while somewhat supporting the association of lead exposure with increased risk of abnormal sperm morphology seen in some previous studies, does not lend support to previously reported associations of sperm density count or infertility with measures of lead exposure. However, the relatively high range of current blood leads, high prevalence of abnormalities in semen quality, and the lack of a control population, suggest that these negative findings should be interpreted with caution.

\section{ACKNOWLEDGMENTS}

The study ensued from an agreement between the Chemical Workers' Industrial Union and the employing company. The study was made possible by grants from the Medical Research Council of South Africa, the De Beers Chairman's Educational Trust, the Medical Faculty of the University of Cape Town, the University of Michigan Office of the Vice President for Research, and the United States Public Health Service. Professor Jonny Myers contributed to the design of the study, while Sister Denise O'Hagan, Oracular Sinqingqi, Brian Wilson, Isaac Ceshembe, Wezile Tshali, and Sister M. Maqina played important roles in its execution. Esme Jordaan of the Medical Research Council provided the univariate analyses of the exposure and covariate data. Jason Roy conducted the analyses of the associations with reproductive outcomes. Mr. Beek of Zeiss Optical loaned a microscope for use in semen analysis. Sister F.A. Gibbs and Ms. Rae Hansen of the East London City Health Department deserve special thanks for the provision of a venue for the collection of semen samples.

\section{REFERENCES}

Alexander BH, Checkoway $\mathrm{H}$, van Neten $\mathrm{C}$, Muller $\mathrm{CH}$, Ewers TG, Kaufman JD, Mueller BA, Vaughan TL, Faustman EM (1996): Semen quality of men employed at a lead smelter. Occup Environ Med 53:411416 .

Assennato G, Paci C, Baser ME, Molinini R, Candela RG, Altamura BM, Giorgino R (1987): Sperm count suppression without endocrine dysfunction in lead-exposed men. Arch Environ Health 42:124-127.

Burgess WA (1995): "Recognition of Health Hazards in Industry: A Review of Materials and Processes.” 2nd Ed. New York: John Wiley \& Sons.

Coste J, Mandereau L, Pessione F, Bregu M, Faye C, Hemon D, Spira A (1991): Lead-exposed workmen and fertility: A cohort study on 354 subjects. Eur J Epidemiol 7:154-158.

Cullen MR, Kayne RD, Robins JM (1984): Endocrine and reproductive dysfunction in men associated with occupational inorganic lead intoxication. Arch Environ Health 39:431-440.

Gennart JP, Buchet JP, Roels H, Ghyselen P, Ceulemans E, Lauwerys R (1992): Fertility of male workers exposed to cadmium, lead, or manganese. Am J Epidemiol 135:1208-1219.

Jiang X, Liang Y, Wang Y (1992): Studies of lead exposure on reproductive system: A review of work in China. Biomed Environ Sci 5:255-275.

Jockenhovel F, Bals-Pratsch M, Bertram HP, Nieschlag E (1990): Seminal lead and copper in fertile and infertile men. Andrologia 22:503-511.

Lancranjan I, Popescu HI, Gavanescu O, Klepsch I, Serbanescu M (1975): Reproductive ability of workmen occupationally exposed to lead. Arch Environ Health 30:396-401.

Lerda D (1992): Study of sperm characteristics in persons occupationally exposed to lead. Am J Ind Med 22:567-571.

Plechaty MM, Noll B, Sunderman FW Jr (1977): Lead concentrations in semen of healthy men without occupational exposure to lead. Ann Clin Lab Sci 7:515-518.

Saaranen M, Suistomaa U, Kantola M, Saarikoski S, Vanha-Perttula T (1987): Lead, magnesium, selenium and zinc in human seminal fluid: Comparison with semen parameters and fertility. Hum Reprod 2:475-479.

Schrader SM, Turner TW, Breitenstein MJ, Simon SD (1988): Longitudinal study of semen quality of unexposed workers. I. Study overview. Reprod Toxicol 2:183-190.

Thomas JA, Brogan WC III (1983): Some actions of lead on the sperm and on the male reproductive system. Am J Ind Med 4:127-134.

Wildt K, Eliasson R, Berlin M (1983): Effects of occupational exposure to lead on sperm and semen. In Clarkson TW, Nordberg GF, Sager PR (eds): "Reproductive and Developmental Toxicity of Metals." New York: Plenum Press.

World Health Organization (1992): "WHO Laboratory Manual for the Examination of Human Semen and Semen-Cervical Mucus Interaction.' Cambridge: Cambridge University Press. 